\title{
Roles of Aquaporins in Setaria viridis Stem Development and Sugar Storage
}

\begin{abstract}
Samantha A. McGaughey 1,2, Hannah L. Osborn ${ }^{3}$, Lily Chen ${ }^{1,3}$, Joseph L. Pegler ${ }^{1}$, Stephen D. Tyerman ${ }^{2}$, Robert T. Furbank ${ }^{3}$, Caitlin S. Byrt ${ }^{2 *}$ and Christopher P. L. Grof ${ }^{1+}$

${ }^{1}$ Centre for Plant Science, School of Environmental and Life Sciences, University of Newcastle, Callaghan, NSW, Australia, ${ }^{2}$ Australian Research Council Centre of Excellence in Plant Energy Biology, Waite Research Institute and School of Agriculture, Food and Wine, University of Adelaide, Glen Osmond, SA, Australia, ${ }^{3}$ Australian Research Council Centre of Excellence for Translational Photosynthesis, College of Medicine, Biology and Environment, Australian National University, Canberra, ACT, Australia
\end{abstract}

Setaria viridis is $\mathrm{a}_{4}$ grass used as a model for bioenergy feedstocks. The elongating internodes in developing $S$. viridis stems grow from an intercalary meristem at the base, and progress acropetally toward fully expanded cells that store sugar. During stem development and maturation, water flow is a driver of cell expansion and sugar delivery. As aquaporin proteins are implicated in regulating water flow, we analyzed elongating and mature internode transcriptomes to identify putative aquaporin encoding genes that had particularly high transcript levels during the distinct stages of internode cell expansion and maturation. We observed that SVPIP2;1 was highly expressed in internode regions undergoing cell expansion, and SVNIP2;2 was highly expressed in mature sugar accumulating regions. Gene co-expression analysis revealed SVNIP2;2 expression was highly correlated with the expression of five putative sugar transporters expressed in the $S$. viridis internode. To explore the function of the proteins encoded by SVPIP2;1 and SVNIP2;2, we expressed them in Xenopus laevis oocytes and tested their permeability to water. SvPIP2;1 and SVNIP2;2 functioned as water channels in X. laevis oocytes and their permeability was gated by $\mathrm{pH}$. Our results indicate that SvPIP2;1 may function as a water channel in developing stems undergoing cell expansion and SVNIP2;2 is a candidate for retrieving water and possibly a yet to be determined solute from mature internodes. Future research will investigate whether changing the function of these proteins influences stem growth and sugar yield in S. viridis.

Keywords: aquaporin, stem, water transport, sugar accumulation, grasses

\section{INTRODUCTION}

The panicoid grasses sugarcane (Saccharum officinarum), sorghum (Sorghum bicolor), switchgrass (Panicum virgatum), and miscanthus (Miscanthus $X$ giganteum) provide the majority of soluble sugars and lignocellulosic biomass used for food and biofuel production worldwide (Somerville et al., 2010; Waclawovsky et al., 2010). A closely related grass with a smaller genome, Setaria viridis, is used as a model for these crops in photosynthesis research and for the study of biomass generation and sugar accumulation (Li and Brutnell, 2011; Bennetzen et al., 2012; Brutnell et al., 2015; Martin et al., 2016). The mechanisms that regulate cell expansion and photoassimilate delivery in 
the stems of these grasses are of interest because they influence the yields of soluble sugars and cell wall biomass produced (Byrt et al., 2011).

Grass stems have repeating units consisting of an internode positioned between two nodes that grow from intercalary meristems at the base; sugar, primarily sucrose, accumulates and is stored in mature cells at the top of the internode (Grof et al., 2013). Along this developmental gradient there is also a transition from synthesis and deposition of primary cell walls through to establishment of thicker secondary cell walls. Sucrose that is not used for growth and maintenance is primarily accumulated intracellularly in the vacuoles of storage parenchyma cells that surround the vasculature (Glasziou and Gayler, 1972; HoffmannThoma et al., 1996; Rae et al., 2005) or in the apoplasm (Tarpley et al., 2007). The mature stems of grasses such as sugarcane can accumulate up to $1 \mathrm{M}$ sucrose, with up to $428 \mathrm{mM}$ sucrose stored in the apoplasm (Hawker, 1985; Welbaum and Meinzer, 1990). In addition to a high capacity for soluble sugar storage, carbohydrates are also stored in cell walls of stem parenchyma cells (Botha and Black, 2000; Ermawar et al., 2015; Byrt et al., 2016a).

Historically, increases in sugar yields in the stems of panicoid grasses have been achieved by increasing sugar concentration in stem cells without increasing plant size (McCormick et al., 2009). Sugarcane and sorghum stem sugar content has been increased by years of selecting varieties with the highest culm sucrose content, but these gains have begun to plateau (Grof and Campbell, 2001; Pfeiffer et al., 2010). It may be that we are approaching a physiological ceiling that limits the potential maximum sucrose concentration in the stems of these grasses. Increasing the size of grass stems as a sink may be an effective strategy to increase stem biomass and the potential for greater soluble sugar yield as a relationship exists between stem size and capacity to import and accumulate photoassimilates (sink strength) as soluble sugars or cell wall carbohydrates. Hence, improved stem sugar yields have also been achieved in some sorghum hybrids by expanding stem volume through increased plant height and stem diameter (Pfeiffer et al., 2010; Slewinski, 2012).

In elongating stems, water and dissolved photoassimilates are imported from the phloem into the stem by bulk-flow, or translocation, to drive cell expansion or otherwise be used for growth, development and storage (Schmalstig and Cosgrove, 1990; Wood et al., 1994). In non-expanding storage sinks, water delivering sucrose is likely to be effluxed to the apoplasm and then recycled into the xylem transportation stream to be exported to other tissues (Lang and Thorpe, 1989; Lang, 1990). In addition to vacuolar accumulation of sugars delivered for storage, sugars may also accumulate in the apoplasm with apoplasmic barriers preventing leakage back into the vasculature (Moore, 1995; Patrick, 1997).

The flow of water from the phloem into growth and storage sinks involves the diffusion of water across plant cell membranes facilitated by aquaporins (Kaldenhoff and Fischer, 2006; Zhang et al., 2007). Aquaporins are a highly conserved family of transmembrane channel proteins that enable plants to rapidly and reversibly alter their membrane water permeability or permeability to other solutes depending on the isoform. In maize (Zea mays) and rice (Oryza sativa) genomes 30-70 aquaporin homologs have been identified, respectively (Chaumont et al., 2001; Sakurai et al., 2005). These large numbers of isoforms can be divided into five subfamilies by sequence homology; plasma membrane intrinsic proteins (PIPs), tonoplast intrinsic proteins (TIPs), nodulin-like intrinsic proteins (NIPs), and small basic intrinsic proteins (SIPs; Johanson and Gustavsson, 2002). In dicotyledonous plants but not monocotyledonous plants there is also a group referred to as $\mathrm{X}$ intrinsic proteins (XIPs; Danielson and Johanson, 2008).

As aquaporins have important roles in controlling water potential, they are prospective targets for manipulating stem biomass and sugar yields (Maurel, 1997). The crucial role of aquaporins in water delivery to expanding tissues and water recycling in mature tissues is indicated by their high expression in these regions (Barrieu et al., 1998; Chaumont et al., 1998; Wei et al., 2007). Here, we explore the transcriptional regulation of aquaporins in meristematic, expanding, transitional and mature $S$. viridis internodal tissues to identify candidate water channels involved in cell expansion and water recycling after sugar delivery in mature internode tissues.

\section{MATERIALS AND METHODS}

\section{Phylogenetic Tree}

Setaria viridis aquaporins were identified from S. italica (Azad et al., 2016), Arabidopsis (Johanson et al., 2001), rice (Sakurai et al., 2005), barley (Hove et al., 2015) and maize (Chaumont et al., 2001) aquaporins, and predicted S. viridis aquaporins from transcriptomic data (Martin et al., 2016) (Supplementary Table S1) using the online HMMER tool phmmer (Finn et al., $2015^{1}$ ). Protein sequences used to generate the phylogenetic tree were obtained for $S$. viridis and $Z$. mays from Phytozome 11.0.5 (S. viridis v1.1, DOE-JGI ${ }^{2}$; last accessed July 19, 2016) (Supplementary Table S2). The phylogenetic tree was generated using the neighbor-joining method in the Geneious Tree Builder program (Geneious 9.0.2).

\section{Elongating Internode Transcriptome Analysis and Aquaporin Candidate Selection}

Expression data on identified $S$. viridis aquaporins was obtained from a transcriptome generated from $S$. viridis internode tissue (Martin et al., 2016). Protein sequences of selected putative aquaporin candidates expressed in the elongating $S$. viridis transcriptome were analyzed by HMMscan (Finn et al., $\left.2015^{1}\right)$.

\section{Plant Growth Conditions}

Seeds of S. viridis (Accession-10; A10) were grown in 2 L pots, two plants per pot, in a soil mixture that contained one part

\footnotetext{
${ }^{1}$ http://www.ebi.ac.uk/Tools/hmmer/

${ }^{2}$ http://phytozome.jgi.doe.gov/
} 
coarse river sand, one part perlite, and one part coir peat. The temperatures in the glasshouse, located at the University of Newcastle (Callaghan, NSW, Australia) were $28^{\circ} \mathrm{C}$ during the day $(16 \mathrm{~h})$ and $20^{\circ} \mathrm{C}$ during the night $(8 \mathrm{~h})$. The photoperiod was artificially extended from 5 to 8 am and from 3 to 9 pm by illumination with $400 \mathrm{~W}$ metal halide lamps suspended $\sim 40 \mathrm{~cm}$ above the plant canopy. Water levels in pots were maintained with an automatic irrigation system that delivered water to each pot for 2 min once a day. Osmocote ${ }^{\circledR}$ exact slow release fertilizer (Scotts Australia Pty Ltd, Sydney, NSW, Australia) was applied at 20 g per pot, 2 weeks post-germination. Additional fertilization was applied using $\mathrm{Wuxal}^{\circledR}$ liquid foliar nutrient and Wuxal ${ }^{\circledR}$ calcium foliar nutrient (AgNova Technologies, Box Hill North, VIC, Australia) alternately each week.

\section{Harvesting Plant Tissues, RNA Extraction, and cDNA Library Synthesis}

Harvesting of plant material from a developing internode followed Martin et al. (2016). Total RNA was isolated from plant material ground with mortar and pestle cooled with liquid nitrogen, using Trizol ${ }^{\circledR}$ Reagent (Thermo Fisher Scientific, Scoresby, VIC, Australia) as per manufacturer's instruction. Genomic DNA was removed using an Ambion TURBO DNase Kit (Thermo Fisher Scientific) following the manufacturer's instructions. cDNA was synthesized from $230 \mathrm{ng}$ of isolated RNA from the cell expansion, transitional, and maturing developmental zones as described in Martin et al. (2016) using the Superscript III cDNA synthesis kit (Thermo Fisher Scientific) with an oligo $\mathrm{d}(\mathrm{T})$ primer and an extension temperature of $50^{\circ} \mathrm{C}$ as per the manufacturer's instructions.

\section{Reverse-Transcriptase Quantitative PCR (RT-qPCR)}

Reverse-transcriptase-qPCR was performed using a Rotor-Gene Q (QIAGEN, Venlo, Netherlands) and GoTaq ${ }^{\circledR}$ Green Master Mix 2x (Promega, Madison, WI, USA). A two-step cycling program was used following the manufacturer's instructions. The green channel was used for data acquisition. Gene expression of the candidate genes was measured as relative to the housekeeper S. viridis PP2A (SvPP2A; accession no.: Sevir.2G128000). The $P P 2 A$ gene was selected as a housekeeper gene because it is established as a robust reference gene in many plant species (Czechowski et al., 2005; Klie and Debener, 2011; Bennetzen et al., 2012) and it was consistently expressed across the developmental internode gradient in the transcriptome and cDNA libraries (Martin et al., 2016; Supplementary Figure S1). The forward (F) and reverse (R) primers used for RT-qPCR for were: SvPIP2;1-F (5'-CTCTACATCGTGGCGCAGT$\left.3^{\prime}\right)$ and SvPIP2;1-R (5'-ACGAAGGTGCCGATGATCT-3'), and SvNIP2;2-F (5'-AGTTCACGGGAGCGATGT- $\left.3^{\prime}\right)$ and SvNIP2;2-R (5'-CTAACCCGGCCAACTCAC-3'). SvPIP2;1 and SvNIP2;2 primer sets amplified 161 and 195 base pair fragments from the CDS, respectively. SvPP2A primer set sequences were SvPP2A-F (5'-GGCAACAAGAAGCTCACTCC-3') and SvPP2A-R ( $5^{\prime}$-TTGCACATCAATGGAATCGT- $\left.3^{\prime}\right)$ and amplified a 164 base pair fragment from the $3^{\prime}$ UTR.

\section{Gene Co-expression Network Analysis}

Raw FPKM values of putative aquaporins and sugar transporters were extracted from the $S$. viridis elongating internode transcriptome (Martin et al., 2016). Putative S. viridis sugar transporters from the Sucrose Transporter (SUT), Sugar Will Eventually be Exported Transporter (SWEET), and Tonoplast Monosaccharide Transporter (TMT) families were identified by homology to rice SUT, SWEET, and TMT genes (Supplementary Table S3; Supplementary Figures S2-S4). FPKM values were normalized by $\log _{2}$ transformation and Pearson's correlation coefficients calculated by Metscape (Karnovsky et al., 2012). A gene network was generated for Pearson's correlation coefficients between 0.8 and 1.0 and visualized with the Metscape app in Cytoscape v3.4.0. Significance of Pearson's correlation coefficients were calculated using SPSS (IBM Corp. Released 2013. IBM SPSS Statistics for Windows, Version 22.0. Armonk, NY, USA) (Supplementary Table S4). The $1.5 \mathrm{~Kb} 5^{\prime}$ promoter region, directly upstream of the transcriptional start site, of the two aquaporin candidates and the highly correlated putative sugar transporter genes were screened for the presence of cis-acting regulatory elements registered through the PlantCARE online database (Lescot et al., 2002 ${ }^{3}$ ) and cis-acting elements of Arabidopsis and rice SUT genes reported by Ibraheem et al. (2010).

\section{Photometric Swelling Assay}

Extracted consensus coding sequences for SVPIP2;1 and SvNIP2;2, from S. viridis transcriptome data (Martin et al., 2016), were synthesized commercially by GenScript (Piscataway, NJ, USA). SvPIP2;1 and SvNIP2;2 cDNA fragments were inserted into a gateway enabled pGEMHE vector. pGEMHE constructs were linearized using NheI (New England Biolabs, Ipswich, MA, USA) and purified using the MinElute PCR Purification Kit (QIAGEN). Complimentary RNA (cRNA) for SvPIP2;1 and $S v N I P 2 ; 2$ was transcribed using the Ambion mMessage mMachine Kit (Life Technologies, Carlsbad, CA, USA).

Xenopus laevis oocytes were injected with $46 \mathrm{ng}$ of SvPIP2;1 or $S v N I P 2 ; 2$ cRNA in $46 \mu \mathrm{L}$ of water, or $46 \mu \mathrm{L}$ of water alone as a control. Injected oocytes were incubated for $72 \mathrm{~h}$ in Ca-Ringer's solution. Prior to undertaking permeability assays oocytes were transferred into ND96 solution $\mathrm{pH} 7.4(96 \mathrm{mM}$ $\mathrm{NaCl}, 2 \mathrm{mM} \mathrm{KCl}, 1.8 \mathrm{mM} \mathrm{CaCl}_{2}, 1 \mathrm{mM} \mathrm{MgCl}_{2}, 500 \mu \mathrm{g} \cdot \mathrm{mL}^{-1}$ Streptomycin, $500 \mu \mathrm{g} \cdot \mathrm{mL}^{-1}$ Tetracycline; $204 \mathrm{osmol} / \mathrm{L}$ ) and allowed to acclimate for $30 \mathrm{~min}$. Oocytes were then individually transferred into a 1:5 dilution of ND96 solution (42 osmol/L), $\mathrm{pH} 7.4$, and swelling was measured for 1 min for SvPIP2;1 injected oocytes and 2 min for SvNIP2;2 injected oocytes. Oocytes were viewed under a dissecting microscope (Nikon SMZ800 light microscope, Japan) at $2 \times$ magnification. The changes in volume were captured with a Vicam color camera (Pacific Communications, Australia) at $2 \times$ magnification and recorded with IC Capture 2.0 software (The Imagine Source, US) as AVI format video files. Images were acquired every $2.5 \mathrm{~s}$ for 2 min measurements and every $2 \mathrm{~s}$ for $1 \mathrm{~min}$ measurements. The osmotic permeability $\left(P_{f}\right)$ was calculated for water injected

\footnotetext{
${ }^{3}$ http://bioinformatics.psb.ugent.be/webtools/plantcare/html/
} 
and cRNA injected oocytes from the initial rate of change in relative volume $\left(d V_{r e l} / d t\right)_{I}$ determined from the cross sectional area images captured assuming the oocytes were spherical:

$$
P_{\mathrm{f}}=\frac{V_{\mathrm{i}} \times\left(d V_{\mathrm{rel}} / d t\right)_{\mathrm{i}}}{A_{\mathrm{i}} \times V_{\mathrm{w}} \times \Delta C_{0}},
$$

Where $V_{\mathrm{i}}$ and $A_{\mathrm{i}}$ are the initial volume and area of the oocyte, respectively, $V_{\mathrm{W}}$ is the partial molar volume of water and $\Delta C_{o}$ is the change in external osmolality. The osmolality of each solution was determined using a Fiske ${ }^{\circledR} 210$ Micro-Sample freezing point osmometer (Fiske, Norwood, MA, USA). pH inhibition of oocyte osmotic permeability was determined as above where oocytes where bathed in 1:5 diluted ND96 solution with the addition of $50 \mathrm{~mm}$ Na-Acetate, $\mathrm{pH}$ 5.6. Topological prediction models of SvPIP2;1 and SvNIP2;2 were generated in TMHMM ${ }^{4}$ (Krogh et al., 2001) and TMRPres-2D (Spyropoulos et al., 2004) to assess potential mechanisms of $\mathrm{pH}$ gating.

\section{RESULTS}

\section{Identification of Putative Setaria viridis Aquaporins}

Previously published $S$. viridis elongating internode transcriptome data (Martin et al., 2016), and protein sequences of aquaporins identified in Arabidopsis, S. italica, barley, maize and rice were used to identify genes predicted to encode aquaporins that were highly expressed in stages of cell expansion and sugar accumulation. The nomenclature assigned to the putative aquaporins followed their relative homology to previously named maize aquaporins determined by phylogenetic analysis of protein sequences (Chaumont et al., 2001; Figure 1). S. viridis proteins separated as expected into the major aquaporin subfamilies referred to as PIPs, TIPs, NIPs, and SIPs. Within S. viridis 41 full length aquaporins were identified: 12 PIPs, 14 TIPs, 12 NIPs, and three SIPs. One predicted aquaporin identified in the genome, transcript Sevir.6G061300.1, has very high similarity to SvNIP5;3 (Sevir.6G06000.1) but may be a pseudogene as it has two large deletions in the transcript relative to SvNIP5;3. Sevir.6G061300.1 only encodes for two out of the typical six transmembrane domains characteristic of aquaporins, and no transcripts have been detected in any of the $S$. viridis RNA-seq libraries available through the Joint Genome Institute (JGI) Plant Gene Atlas Project (Grigoriev et al., 2011). Another truncated NIP-like transcript, Sevir.5G141800.1, was identified. It is predicted to encode a protein 112 amino acids in length with only two transmembrane domains. As it is unlikely to generate an individually functioning aquaporin it has not been named. However, unlike Sevir.6G061300.1, Sevir.5G141800.1 was included in the phylogenetic tree as it was shown to be highly expressed in several tissue types in S. viridis RNA-seq libraries available through the JGI Plant Gene Atlas Project (Grigoriev et al., 2011) and may be of interest to future studies of Setaria aquaporin-like genes.

\footnotetext{
${ }^{4}$ http://www.cbs.dtu.dk/services/TMHMM/
}

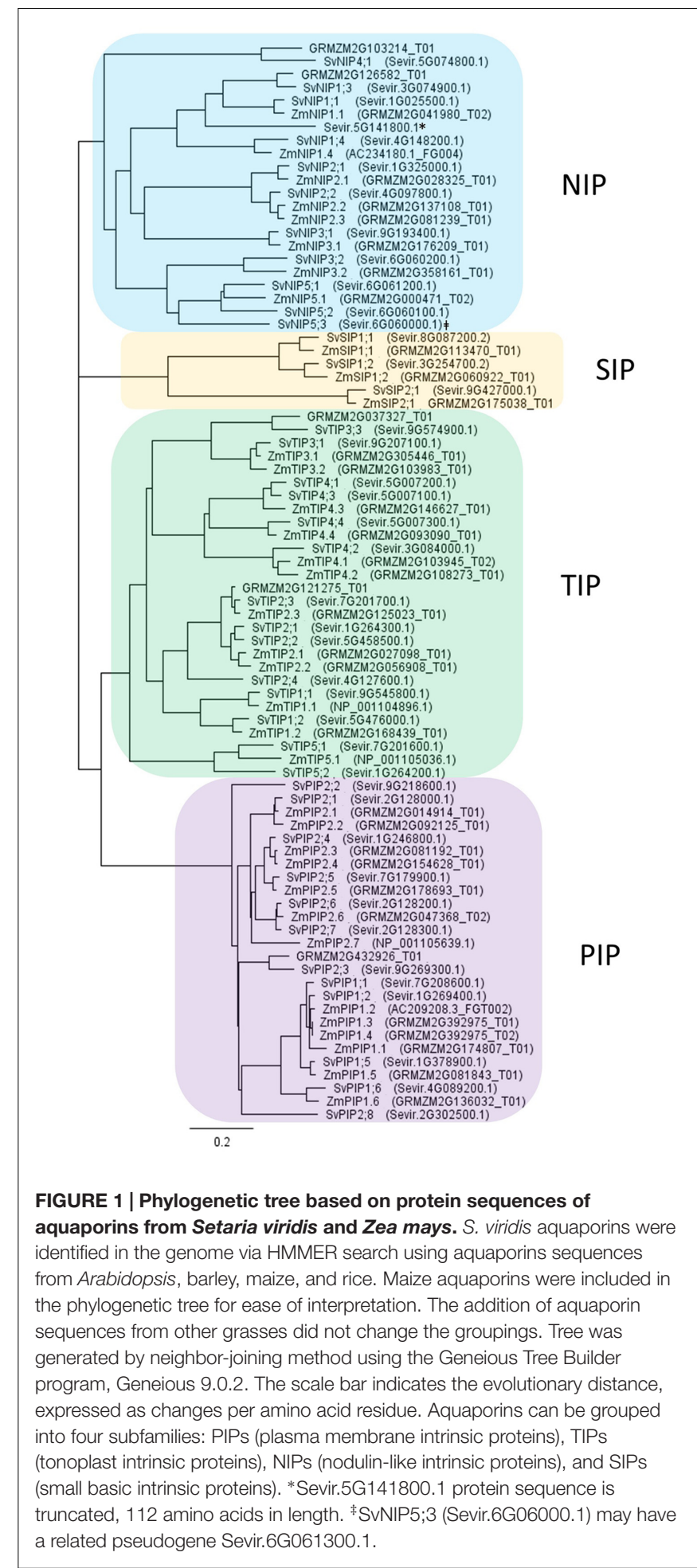

\section{Analysis of Setaria viridis Aquaporin Transcripts in Stem Regions}

We compared the relative transcript levels of putative S. viridis aquaporin encoding genes in the different developmental regions of an elongating internode (Figure 2). We observed that SvPIP1;2 


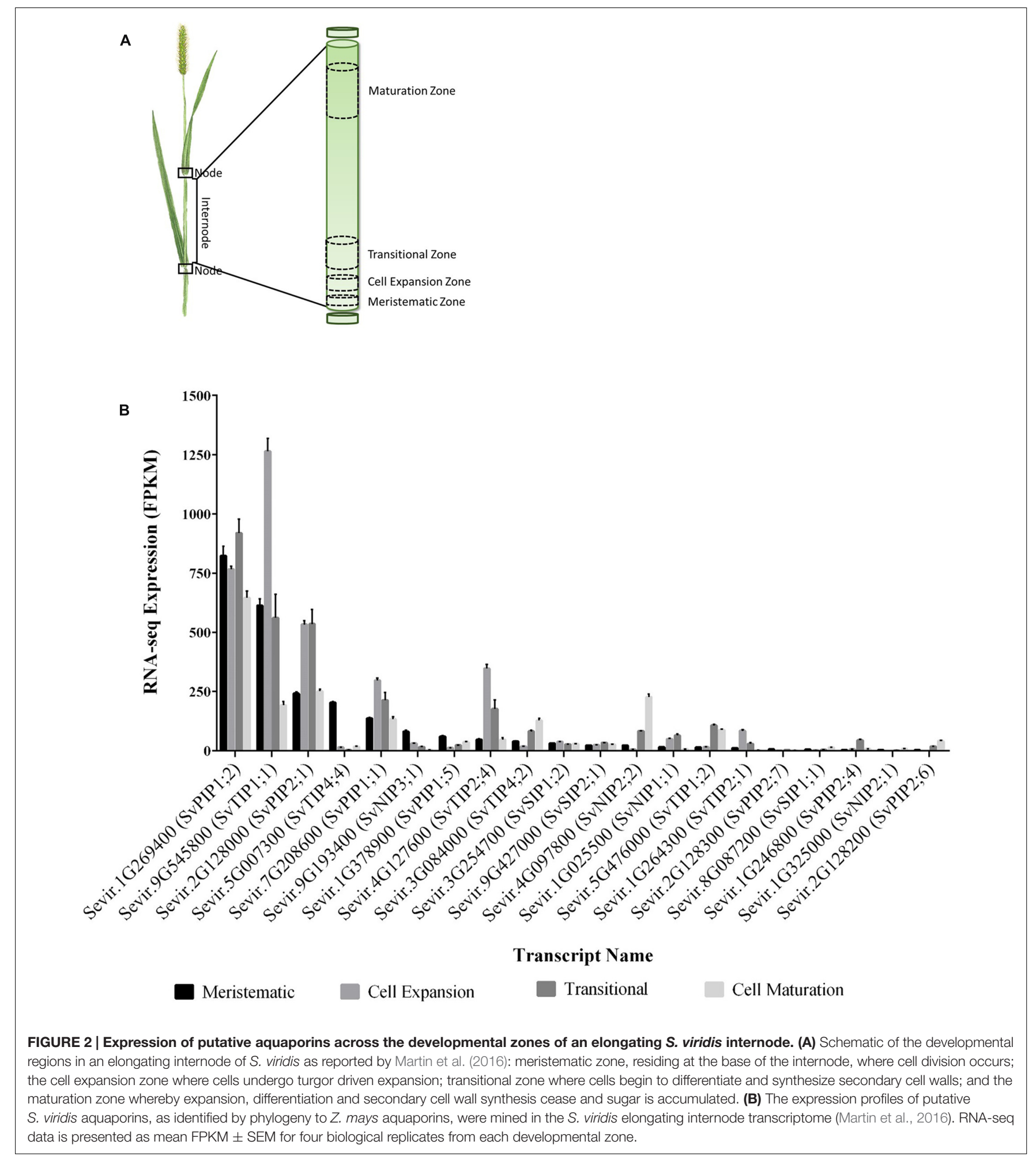

transcripts were abundant in all regions; and SvTIP1;1 transcripts were also abundant, particularly in cell expansion regions. SvPIP2;1, SvPIP1;1, SvTIP2;2, and SvTIP2;1 transcripts were detected in all regions with the highest transcript levels in cell expansion and transitional regions. Transcripts for SvTIP4;4,
SvNIP3;1, and SvPIP1;5 were highest in the meristem relative to other regions; whereas SvTIP4;2, SvNIP2;2, and SvTIP1;2 transcripts were at their highest in transitional or mature regions. Low transcript levels were observed for $S v S I P 1 ; 2$, SvNIP1;1, and $S v P I P 2 ; 4$ in all regions, with maximum transcripts for 
SvNIP1;1 and SvPIP2;4 detected in the transitional region, and very low transcript levels were detected for SvPIP2;6, SvSIP1;1, and SvNIP2;1.

Overall the highest aquaporin transcript levels detected across the internode developmental zones were those of SvPIP1;2 (Figure 2). Previous research has indicated that the related ZmPIP1;2 interacts with PIP2 subgroup proteins targeting PIP2s to plasma membrane, and a number of PIP1 aquaporins are not associated with osmotic water permeability when expressed alone in oocytes (Fetter et al., 2004; Luu and Maurel, 2005; Zelazny et al., 2007). Our interest lay in identifying water permeable aquaporins that might be preferentially involved in delivering water to the growing stem cells and in sucrose accumulation in mature stem regions. As candidates SvPIP2;1 and SvNIP2;2 met these criteria we focussed on these two genes. SvPIP2; 1 had the high transcript levels in the region of cell expansion and transcript levels of $S v N I P 2 ; 2$ were highest in mature stem regions (Figure 2B). The protein sequences of SvPIP2;1 and SvNIP2;2 were analyzed by the HMMER tool HMMscan which identified these candidates as belonging to the aquaporin (Major Intrinsic Protein) protein family.

To confirm our RNA-seq expression profile observations, we measured the transcript levels of SvPIP2;1 and SvNIP2;2 in the $S$. viridis internode regions by RT-qPCR. Stem samples were harvested from $S$. viridis plants grown under glasshouse conditions with the light period artificially supplemented by use of metal halide lamps to replicate as closely as possible the conditions used by Martin et al. (2016) for the RNA-seq analysis. We assessed the relative fold change of gene expression normalized to the cell expansion zone and similar trends were observed for the RT-qPCR expression data compared to the RNAseq transcriptome data (Figure 3). SvPIP2;1 transcript levels were high in the cell expansion region and decreased toward the maturation region and $S v N I P 2 ; 2$ transcript levels were highest in mature stem tissues.

We are interested in the coordination of water and sugar transport related processes in developing grass stems. As a tool to investigate this, we further analyzed the stem transcriptome data to test whether any aquaporin and sugar transport related genes were co-expressed. Putative S. viridis sugar transporters were identified from the internode transcriptome (Martin et al., 2016) by homology to the rice sugar transporter families: SUTs, SWEETs, and TMTs (Supplementary Figures S2-S4). A co-expression gene network of the aquaporins and sugar transporters expressed in the $S$. viridis stem was generated in Cytoscape v3.4.0 using Pearson's correlation coefficients calculated by MetScape (Karnovsky et al., 2012) (Figure 4). This analysis revealed that for a number of aquaporins and sugar transport related genes there was a high correlation in expression: SvPIP2;1 expression correlated with the expression of SvPIP2;3, SvTIP2;1, and SvNIP1;1 (0.8-0.9); and the correlation coefficients for co-expression of SvPIP2;1 with SvPIP2;5, SvTIP4;1, SvTIP1;2, and SWEET1a were in the range of $0.8-0.9$. Most notable was the high correlation (0.95-1.0) of expression of SvNIP2;2 with sugar transport related genes SvSUT5, SvSUT1, SvSWEET4a and with SvTIP4;2 and SvPIP2;6. The correlation between expression of SvNIP2;2 and SvSWEET13b and SvSWEET16 was also high
(0.9-0.95). The cis-acting regulatory elements of the promoter regions of the aquaporin candidates $S v N I P 2 ; 2$ and SvPIP2;1, and the putative sugar transporter genes SvSUT1, SvSUT5, and SvSWEET4a were analyzed (Supplementary Figure S5). There was no obvious relationship between the correlation of expression of SVNIP2;2 and SVSUT1, SVSUT5 and SvSWEET4a and their cis-acting regulatory elements.

\section{Characterisation of Setaria viridis PIP2;1 and NIP2;2 in Xenopus laevis Oocytes}

To explore whether the proteins encoded by $S v P I P 2 ; 1$ and $S v N I P 2 ; 2$ function as water channels they were expressed in the heterologous $X$. laevis oocytes system. Water with or without $46 \mathrm{ng}$ of SvPIP2;1 and SvNIP2;2 cRNA was injected into oocytes and the swelling of these oocytes in response to bathing in a hypo-osmotic solution ( $\mathrm{pH} 7.4)$ was measured (Figure 5A). The osmotic permeability $\left(P_{f}\right)$ of cRNA injected oocytes was calculated and compared to the osmotic permeability of water injected oocytes. Water injected oocytes had a $P_{f}$ of $0.60 \pm 0.08 \times 10^{-2} \mathrm{~mm} \mathrm{~s}^{-1}$. Relative to water injected control oocytes SvPIP2;1 and SvNIP2;2 cRNA injected oocytes had significantly higher $P_{f}$ of $14.13 \pm 1.66 \times 10^{-2} \mathrm{~mm} \mathrm{~s}^{-1}$ and $3.22 \pm 0.28 \times 10^{-2} \mathrm{~mm} \mathrm{~s}^{-1}$, respectively $(p<0.05)$.

The effect of lowering oocyte cytosolic $\mathrm{pH}$ was determined by bathing oocytes in an external hypo-osmotic solution at pH 5.6 with the addition of Na-Acetate (Figure 5B). Reduced osmotic permeability of the cRNA injected oocyte membrane was observed in response to the low $\mathrm{pH}$ treatment. A reduction in $P_{f}$ was observed for SvPIP2;1 and SvNIP2;2 cRNA injected oocytes bathed in an external hypo-osmotic solution at $\mathrm{pH} 5.6$ relative to the $\mathrm{pH} 7.4$ solution indicating that SvPIP2;1 and SvNIP2;2 have $\mathrm{pH}$ gating mechanisms (Figure 5B). Water injected oocytes in the pH $5.6 \mathrm{Na}$-Acetate solution had $P_{f}$ of $0.84 \pm 0.13 \times 10^{-2} \mathrm{~mm}$ $\mathrm{s}^{-1}$. SvNIP2;2 and SvPIP2;1 cRNA injected oocytes in the pH 5.6 solution had significantly lower $P_{f}$ of $2.46 \pm 0.32 \times 10^{-2} \mathrm{~mm} \mathrm{~s}^{-1}$ and $0.97 \pm 0.13 \times 10^{-2} \mathrm{~mm} \mathrm{~s}^{-1}$, respectively, compared to those in $\mathrm{pH} 7.4$ solution $(p<0.05)$. SvPIP2;1 and SvNIP2;2 associated osmotic permeability and $\mathrm{pH}$ gating observations indicate that these proteins can function as water channels. The mechanism of $\mathrm{pH}$ gating for other plant aquaporins is the protonation of a Histidine residue in the Loop D structure; topological modeling of SvPIP2;1 and SvNIP2;2 predicted that the Loop D of SvPIP2;1 contains a Histidine residue while SvNIP2;2 Loop D does not contain a His residue (Supplementary Figure S6).

\section{DISCUSSION}

\section{Roles of Aquaporins in Grass Stem Development}

On the basis of amino acid sequence comparison with known aquaporins in Arabidopsis, rice and maize, the genomes of sugarcane, sorghum and $S$. italica include 42,41 , and 42 predicted aquaporin encoding genes, respectively (da Silva et al., 2013; Reddy et al., 2015; Azad et al., 2016). In S. viridis 41 aquaporin encoding genes were identified that group into four clades 


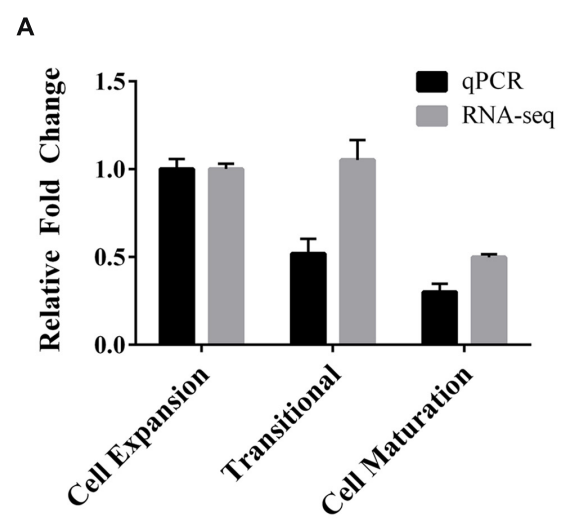

Developmental Zone

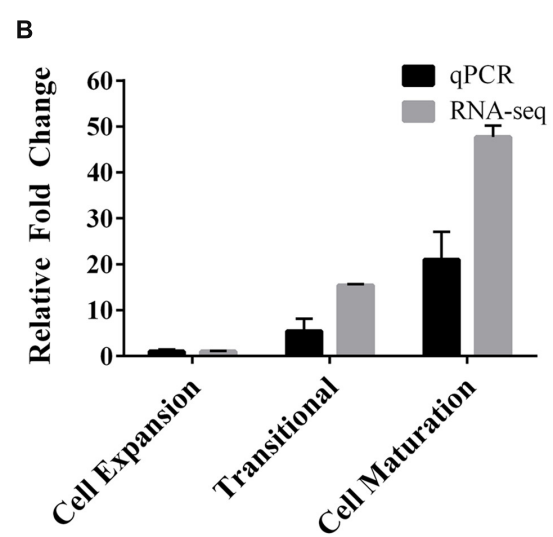

Developmental Zone

FIGURE 3 | Comparison of relative fold changes between RNA-seq and RT-qPCR of SvPIP2;1 and SvNIP2;2 in an elongating internode of S. viridis. (A) SVPIP2;1. (B) SVNIP2;2. Data is mean relative fold change in expression \pm SEM. Data for RNA-seq and RT-qPCR was normalized relative to the cell expansion zone expression level.

corresponding to NIPs, TIPs, SIPs, and PIPs (Figure 1). We note that Azad et al. (2016) named the Setaria aquaporins in an order consecutive with where they are found in the genome. For ease of comparing related aquaporins in $\mathrm{C}_{4}$ grasses of interest, we named the Setaria aquaporins based on their homology to previously named maize aquaporins (Figure 1) (Chaumont et al., 2001), of course high homology and the same name does not infer the same function. In the $S$. viridis elongating internode transcriptome, we detected transcripts for 19 putative aquaporin encoding genes, including 5 NIPs, 6 TIPs, 2 SIPs, and 6 PIPs (Figures 2 and 3; Martin et al., 2016). In mature S. viridis internode tissues, the transcript levels of TIPs and NIPs was generally low with the exception of SvNIP2;2, SvTIP4;2, and SvTIP1;2. In a sorghum stem transcriptome report investigating SWEET gene involvement in sucrose accumulation, we note that transcripts for all 41 sorghum aquaporins were detected in pith and rind tissues in 60-day-old plants (Reddy et al., 2015; Mizuno et al., 2016). Of those 41 aquaporins the expression of 16 , primarily NIPs and TIPs, was relatively low. However, PIP1;2, PIP2;1, and NIP2;2 homologs were all highly expressed in pith and rind of sorghum plants after heading, which is consistent with our findings for the $S$. viridis homologs of these genes (Figure 2; Mizuno et al., 2016). Comparisons with other gene expression studies for $\mathrm{C}_{4}$ grass stem tissues were not possible as in most studies the internode tissue has not been separated into different developmental zones or the study has not reported aquaporin expression (Carson and Botha, 2000, 2002; Casu et al., 2007).

\section{Relationships between Sink Strength, Sink Size, Water Flow, and the Function of Aquaporins}

The molecular and physiological mechanisms that determine stem cell number and cell size in turn determine the capacity of the stem as a sink (Ho, 1988; Herbers and Sonnewald, 1998).
Examples have been reported in the literature where stem volume and sucrose concentration has been increased, in sugarcane and sorghum, by increasing cell size (Slewinski, 2012; Patrick et al., 2013). Larger cell size may improve sink strength by increasing membrane surface area available to sucrose transport (increasing import capacity), increasing single cell capacity to accumulate greater concentrations of sucrose in parenchyma cell vacuoles due to increased individual cell volume (increasing storage capacity), and increasing lignocellulosic biomass.

Cell expansion and growth are highly sensitive to water potential. This is because expansion requires a continuous influx of water into the cell to maintain turgor pressure (Hsiao and Acevedo, 1974; Cosgrove, 1986, 2005). The diffusion of water across a plant cell membrane is facilitated by aquaporins (Kaldenhoff and Fischer, 2006). Aquaporins function throughout all developmental stages, but several PIP aquaporins have been found to be particularly highly expressed in regions of cell expansion (Chaumont et al., 1998; Maurel et al., 2008; Besse et al., 2011). Here, we report that in the S. viridis internode, SvPIP2;1 was highly expressed in regions undergoing cell expansion (Figure 2). Positive correlations have been reported for the relationship between PIP mRNA and protein expression profiles of PIP isoforms in the expanding regions of embryos, roots, hypocotyls, leaves, and reproductive organs indicating that gene expression is a key mechanisms to regulate PIP function (Maurel et al., 2002; Hachez et al., 2008; Liu et al., 2008). Therefore, high expression of SvPIP2;1 in the expanding zone of S. viridis internodes indicates that this gene may be involved in the process of water influx in this tissue to maintain turgor pressure for growth.

The roles of a number of PIP proteins in hydraulic conductivity in plant roots and leaves have been reported but PIP function in stems is largely unexplored. The regulation of the hydraulic properties of expanding root tissues by PIP expression was analyzed by Péret et al. (2012) and they reported 


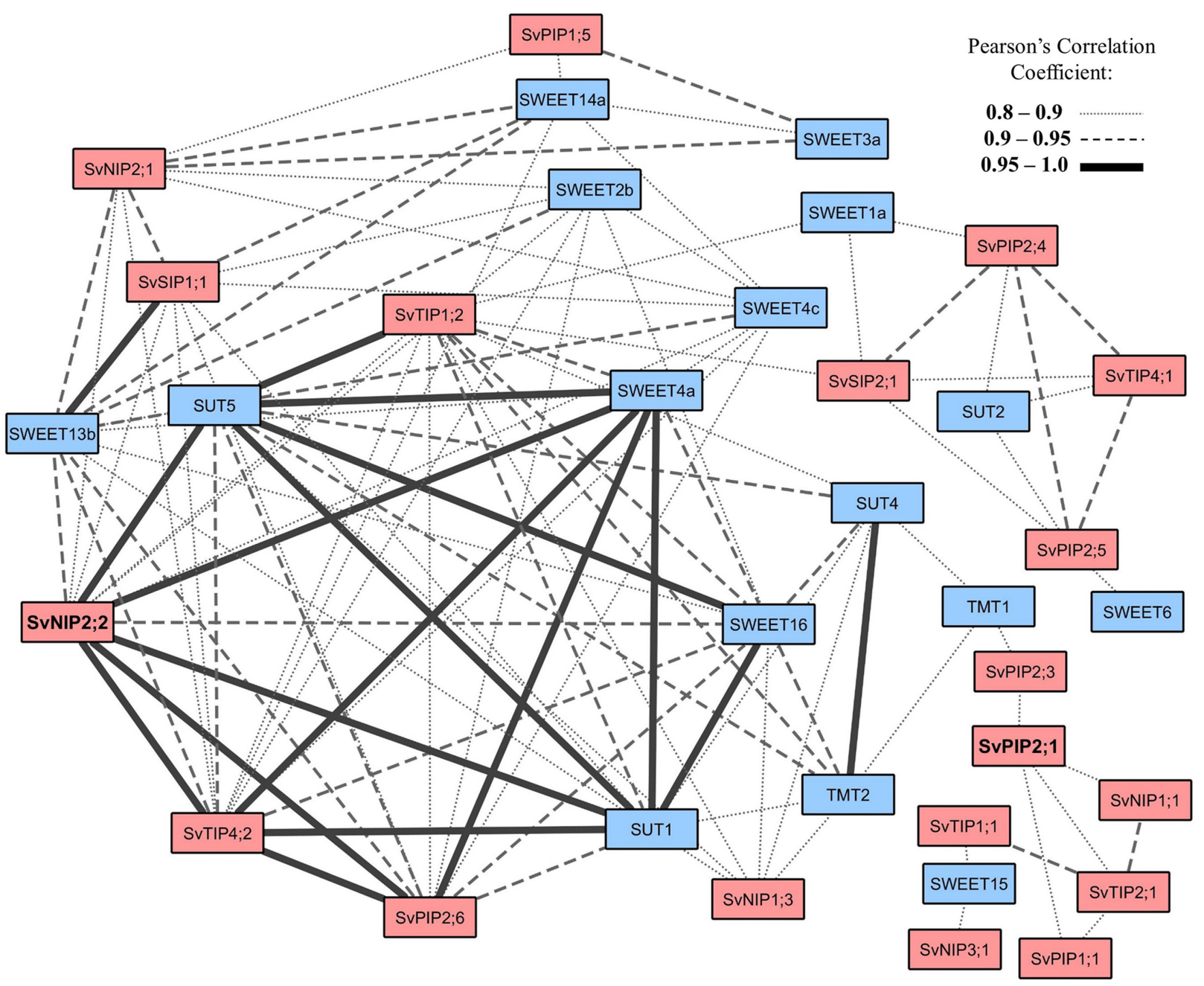

FIGURE 4 | Co-expression network of putative S. viridis aquaporin and sugar transporter genes identified in an elongating internode. The co-expressed gene network was generated from the stem specific aquaporins (Figure 2) and sugar transporters identified in the S. viridis elongating internode transcriptome reported by Martin et al. (2016). Raw FPKM values were $\log _{2}$ transformed and Pearson's correlation coefficients $(0.8-1.0)$ were calculated in the MetScape app in Cytoscape v3.4.0. Sugar transporters in the S. viridis elongating internode were identified by homology to rice sugar transporter genes (Supplementary Figures S2-S4). Sugar transport related genes are color filled with blue and aquaporin genes with orange. SVNIP2;2 and SvPIP2;1 are in bold font.

that auxin mediated reduction of Arabidopsis thaliana (At) PIP gene expression resulted in delayed lateral root emergence. Previously AtPIP2;2 anti-sense mutants were reported to have lower (25-30\%) hydraulic conductivity of root cortex cells than control plants (Javot et al., 2003). PIP2 family aquaporins, involved in cellular water transport in roots have also been linked to water movement in leaves, seeds, and reproductive organs (Schuurmans et al., 2003; Bots et al., 2005). The roles of PIP proteins in maintenance of hydraulic conductivity and cell expansion in stems are likely to be equally as important as the roles reported for PIPs in the expanding tissues of roots and leaves. One study in rice reported OsPIP1;1 and OsPIP2;1 as being highly expressed in the zone of cell expansion in rapidly growing internodes (Malz and Sauter, 1999). Expression analysis of sugarcane genes associated with sucrose content identified that some unnamed PIP isoforms were highly expressed in immature internodes, and in high sugar yield cultivars (PapiniTerzi et al., 2009). Proteins from the PIP2 subfamily in particular in maize, spinach and Arabidopsis have been shown to be highly permeable to water (Johansson et al., 1998; Chaumont et al., 2000; Kaldenhoff and Fischer, 2006). Here, we demonstrate, by expression of SvPIP2;1 in Xenopus oocytes and analysis of water permeability, that this protein functions as a water channel (Figure 5A).

\section{Aquaporin Function and Sugar Accumulation in Mature Grass Stems}

The accumulation of sucrose to high concentrations in panicoid stems rapidly increases with the cessation of cell expansion, which is also associated with the deposition of secondary cell walls (Hoffmann-Thoma et al., 1996). In the mature regions of the stem internodes, imported sucrose is no longer required for 

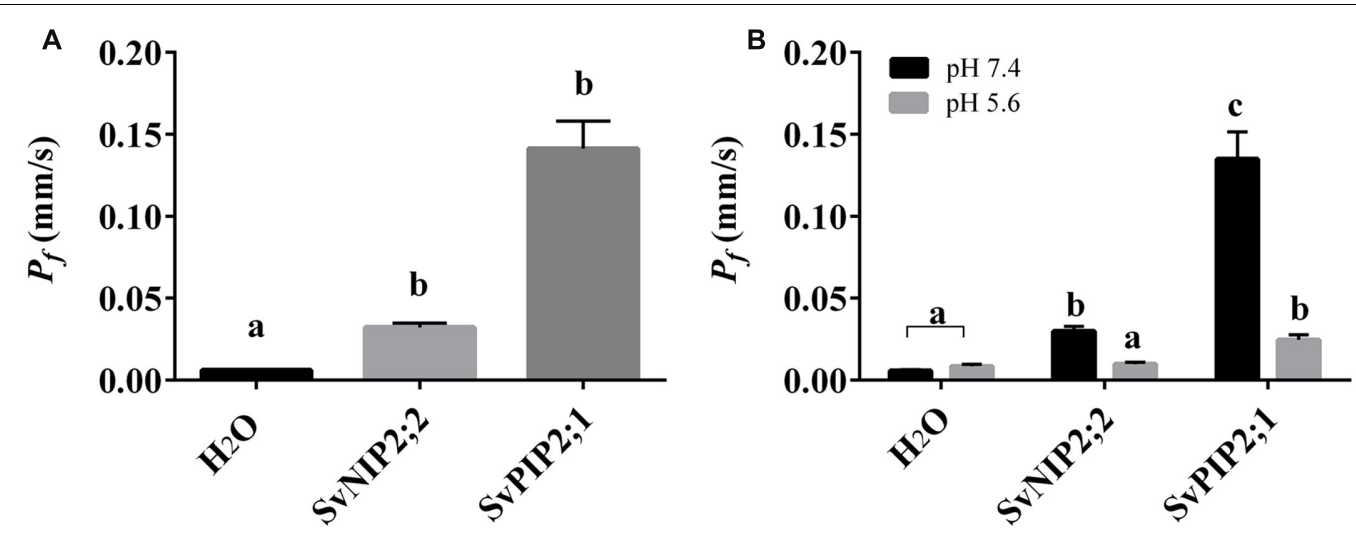

FIGURE 5 | Osmotic permeability $\left(\boldsymbol{P}_{\mathrm{f}}\right)$ of Xenopus laevis oocytes injected with SvNIP2;2 and SvPIP2;1 cRNA. (A) Osmotic permeability $\left(P_{\mathrm{f}}\right)$ of water $\left(\mathrm{H}_{2} \mathrm{O}\right)$ injected and SVNIP2;2 and SVPIP2;1 cRNA (46 ng) injected oocytes. Oocytes were transferred into a hypo-osmotic solution, pH 7.4, and $P_{f}$ was calculated by video monitoring of the rate of oocyte swelling. (B) Effect of lowering oocyte cytosolic pH on osmotic permeability $\left(P_{\mathrm{f}}\right)$ of $\mathrm{H}_{2} \mathrm{O}$ and $\mathrm{SVNIP2} 2 \mathrm{2}$ and $\mathrm{SV} P \mathrm{P} 2 ; 1 \mathrm{cRNA}$ injected oocytes by bathing in hypo-osmotic solution supplemented with $50 \mathrm{mM} \mathrm{Na-acetate,} \mathrm{pH} 5.6, n=12-14$; $\mathrm{a}=$ non-significant; $\mathrm{b}=p<0.05 ; \mathrm{c}=p<0.005$.

growth, development, or as a necessary precursor to structural elements and it is stored in the vacuoles of ground parenchyma cells or the apoplasm (Rae et al., 2009). Phloem unloading and the delivery of sucrose to these storage cells may occur via an apoplasmic pathway as in sorghum or a symplasmic pathway as in sugarcane (Welbaum and Meinzer, 1990; Walsh et al., 2005). The degree of suberisation and/or lignification of cell walls surrounding the phloem may influence stem sucrose storage traits by restricting apoplasmic pathways of sucrose transport. In potato tubers and Arabidopsis ovules a switch between apoplasmic and symplasmic pathways of delivering sucrose to storage sites has been reported (Viola et al., 2001; Werner et al., 2011). Similarly, a switch from symplasmic to apoplasmic transport pathways has been proposed for sorghum as internodes approach maturity (Tarpley et al., 2007; Milne et al., 2015). Both apoplasmic and symplasmic mechanisms of phloem unloading require the maintenance of low sugar concentration in the cytoplasm of parenchymal storage cells. Control of hydrostatic pressure is facilitated by the sequestration of sucrose into the vacuole by tonoplast localized SUTs or into the apoplasm by plasma membrane localized SUTs (Slewinski, 2011). Members of the SUT and TMT families have been shown to function on the tonoplast to facilitate sucrose accumulation in the vacuole (Reinders et al., 2008; Wingenter et al., 2010; Bihmidine et al., 2016). In mature stem tissue plasma membrane localized SWEETs, SUTs, and possibly some NIPs may have a role in transporting sugar into the apoplasm (Milne et al., 2013; Chen, 2014).

The cell maturation zone is characterized by cells that have ceased expansion and differentiation and have realized their sugar accumulation capacity (Rohwer and Botha, 2001; McCormick et al., 2009). In mature sink tissues, the movement of water and dissolved photoassimilates from the phloem to storage parenchyma cells may be driven by differences in solute concentration and hydrostatic pressure (Turgeon, 2010; De Schepper et al., 2013). However, the movement of water and sucrose by diffusion or bulk-flow requires the continued maintenance of low cytosolic sucrose concentrations by accumulation of sucrose into the vacuole or efflux into the apoplasm for storage (Grof et al., 2013). Throughout internode development, the internal cell pressure of storage parenchyma cells in sugarcane remains relatively constant despite increasing solute concentrations toward maturation (Moore and Cosgrove, 1991). As mature cells tend to have heavily lignified cell walls that limit the ability of the protoplast to expand in response to water flux the equilibration of storage parenchyma cell turgor is likely to be achieved by the partitioning of sucrose into the vacuole and apoplasm, and efflux of water into the apoplasm (Moore and Cosgrove, 1991; Vogel, 2008; Keegstra, 2010; Moore and Botha, 2013). Phloem water effluxed into the apoplasm may then be recycled back to the vascular bundles (Welbaum et al., 1992).

Members of the NIPs are candidates for water and neutral solute permeation, and some NIPs could have a role in water and solute efflux to the apoplasm in mature stem cells (Takano et al., 2006; Kamiya et al., 2009; Li et al., 2009; Hanaoka et al., 2014). The NIP subfamily is divided into the subgroups NIP I, NIP II, and NIP III based on the composition of the ar/R selectivity filter (Liu and Zhu, 2010). NIP III subgroup homologs have reported permeability to water, urea, boric acid, and silicic acid (Bienert et al., 2008; Ma et al., 2008; Ma and Yamaji, 2008; Li et al., 2009). In grasses NIP2;2 homologs, from the NIP III subgroup, have been shown to localize to the plasma membrane (Ma et al., 2006).

In the $S$. viridis internode, $S v N I P 2 ; 2$ had relatively high transcript levels in mature stem tissue where sugar accumulates, and it can function as a water channel, although with a relatively low water permeability compared to SvPIP2;1 (Figures 2 and 5A). Our analysis of gene co-expression in stem tissues revealed high correlation between the expression of $S v N I P 2 ; 2$ and five putative $S$. viridis sugar transporter genes (Figure 4). Co-expression can indicate that genes are controlled by the same transcriptional regulatory program, may be functionally related, or be members of the same pathway or protein complex (Eisen et al., 1998; 
Yonekura-Sakakibara and Saito, 2013). The strong correlation between expression of SVNIP2;2 and key putative sugar transport related genes such as SvSUT5, SvSUT1, SvSWEET4a, SvSWEET13b, and SvSWEET16 indicates that they may be involved in a related biological process such as stem sugar accumulation. It is likely that one or more of the SWEETs have roles in transporting sugars out of the stem parenchyma cells into the apoplasm. SvNIP2;2 may be permeable to neutral solutes as well as water and the role of this protein in the mature stem could be in effluxing a solute to adjust osmotic pressure allowing for greater sugar storage capacity. The rice and soybean (Glycine max L.) NIP2;2 proteins are permeable to silicic acid and silicon, respectively (Ma et al., 2006; Zhao et al., 2010; Deshmukh et al., 2013). The deposition of silicic acid into the apoplasm, where it associates with the cell wall matrix as a polymer of hydrated amorphous silica (Epstein, 1994; Ma et al., 2004; Coskun et al., 2016), strengthens the culm to reduce lodging events, and increases plant resistance to pathogens and abiotic stress factors (Mitani, 2005).

SvNIP2;2 water permeability was gated by $\mathrm{pH}$ (Figure 5B). Gating of water channel activity has been reported for PIPs, including SvPIP2;1 (Figure 5B), and for the TIP2;1 isoform found in grapevine (Törnroth-Horsefield et al., 2006; Leitao et al., 2012; Frick et al., 2013). The mechanism of pH gating for these AQPs is the protonation of a Histidine residue located on the cytoplasmic Loop D where site-directed mutagenesis studies of the Loop D His residue results in a loss of $\mathrm{pH}$ dependent water permeability (Tournaire-Roux et al., 2002; Leitao et al., 2012; Frick et al., 2013). However, although SvNIP2;2 water permeability was $\mathrm{pH}$ dependent the predicted Loop D structure does not contain a His residue (Supplementary Figure S5), hence for SvNIP2;2 the mechanism for $\mathrm{pH}$ gating is not clear.

\section{CONCLUSION}

Our observations of high transcript levels of SvPIP2;1 in expanding $S$. viridis stem regions and high transcript levels of SvNIP2;2 in mature stems inspired us to test the function of the proteins encoded by these genes. We found that SvPIP2;1 and SvNIP2;2 can function as $\mathrm{pH}$ gated water channels. We hypothesize that in stem tissues SvPIP2;1 is involved in cell growth and that SvNIP2;2 may facilitate water movement and potentially the flow of other solutes into the apoplasm to sustain solute transportation by bulk-flow, and possibly 'recycle' water used for solute delivery back to the xylem. It is expected

\section{REFERENCES}

Azad, A. K., Ahmed, J., Alum, A., Hasan, M., Ishikawa, T., Sawa, Y., et al. (2016). Genome-wide characterization of major intrinsic proteins in four grass plants and their non-aqua transport selectivity profiles with comparative perspective. PLoS ONE 11:e0157735. doi: 10.1371/journal.pone.0157735

Barrieu, F., Chaumont, F., and Chrispeels, M. J. (1998). High expression of the tonoplast aquaporin ZmTIP1 in epidermal and conducting tissues of maize. Plant Physiol. 117, 1153-1163. doi: 10.1104/pp.117.4.1153

Bennetzen, J. L., Schmutz, J., Wang, H., Percifield, R., Hawkins, J., Pontaroli, A. C., et al. (2012). Reference genome sequence of the that SvPIP2;1 could have additional roles, as other PIP water channels have been shown to also be permeable to $\mathrm{CO}_{2}$, hydrogen peroxide, urea, sodium and arsenic (Siefritz et al., 2001; Uehlein et al., 2003; Mosa et al., 2012; Bienert and Chaumont, 2014; Byrt et al., 2016b). SvNIP2;2 could have roles such as transporting neutral solutes to the apoplasm, as previous studies report silicic acid, urea, and boric acid permeability for other NIPS (Bienert et al., 2008; Ma et al., 2008; Ma and Yamaji, 2008; Li et al., 2009; Deshmukh et al., 2013). Transporting solutes other than sucrose into the apoplasm in mature stem tissues may be an important part of the processes that supports high sucrose accumulation capacity in grass stem parenchyma cells. The next steps in establishing the respective functions of SvPIP2;1 and SvNIP2;2 in stem growth and sugar accumulation in $S$. viridis will require testing of the permeability of these proteins to a range of other solutes and modification of their function in planta.

\section{AUTHOR CONTRIBUTIONS}

CG conceived and designed the work. SM, HO, LC, and JP acquired the data. SM, ST, CB, and CG analyzed and interpreted the data. SM and CB drafted and revised the work. All authors commented on the manuscript. SM, ST, RF, CB, and CG revised the work critically for intellectual content.

\section{FUNDING}

This research was supported by The Australian Research Council (ARC) Centre of Excellence in Plant Energy Biology (CE140100008) and CB (ARC DE150100837).

\section{ACKNOWLEDGMENT}

We thank Wendy Sullivan for preparation of oocytes. We thank Kate Hutcheon for advice on qPCR and Antony Martin for comments on early planning documents and cloning plans.

\section{SUPPLEMENTARY MATERIAL}

The Supplementary Material for this article can be found online at: http://journal.frontiersin.org/article/10.3389/fpls.2016.01815/ full\#supplementary-material

model plant Setaria. Nat. Biotechnol. 30, 555-564. doi: 10.1038/nbt. 2196

Besse, M., Knipfer, T., Miller, A. J., Verdeil, J.-L., Jahn, T. P., and Fricke, W. (2011). Developmental pattern of aquaporin expression in barley (Hordeum vulgare L.) leaves. J. Exp. Bot. 62, 4127-4142. doi: 10.1093/jxb/ err175

Bienert, G. P., and Chaumont, F. (2014). Aquaporin-facilitated transmembrane diffusion of hydrogen peroxide. Biochim. Biophys. Acta. 1840, 1596-1604. doi: 10.1016/j.bbagen.2013.09.017

Bienert, G. P., Thorsen, M., Schüssler, M. D., Nilsson, H. R., Wagner, A., Tamás, M. J., et al. (2008). A subgroup of plant aquaporins facilitate the bi-directional 
diffusion of $\mathrm{As}(\mathrm{OH}) 3$ and $\mathrm{Sb}(\mathrm{OH}) 3$ across membranes. BMC Biol. 6:26. doi: 10.1186/1741-7007-6-26

Bihmidine, S., Julius, B. T., Dweikat, I., and Braun, D. M. (2016). Tonoplast sugar transporters (SbTSTs) putatively control sucrose accumulation in sweet sorghum stems. Plant Signal. Behav. 11:e1117721. doi: 10.1080/15592324.2015. 1117721

Botha, F. C., and Black, K. G. (2000). Sucrose phosphate synthase and sucrose synthase activity during maturation of internodal tissue in sugarcane. Aust. J. Plant Physiol. 27, 81-85.

Bots, M., Feron, R., Uehlein, N., Weterings, K., Kaldenhoff, R., and Mariani, T. (2005). PIP1 and PIP2 aquaporins are differentially expressed during tobacco anther and stigma development. J. Exp. Bot. 56, 113-121.

Brutnell, T. P., Bennetzen, J. L., and Vogel, J. P. (2015). Brachypodium distachyon and Setaria viridis: Model genetic systems for the grasses. Annu. Rev. Plant Biol. 66, 465-485. doi: 10.1146/annurev-arplant-042811-105528

Byrt, C. S., Betts, N. S., Tan, H.-T., Lim, W. L., Ermawar, R. A., Nguyen, H. Y., et al. (2016a). Prospecting for energy-rich renewable raw materials: sorghum stem case study. PLoS ONE 11:e0156638. doi: 10.1371/journal.pone. 0156638

Byrt, C. S., Grof, C. P. L., and Furbank, R. T. (2011). C4 plants as biofuel feedstocks: optimising biomass production and feedstock quality from a lignocellulosic perspective. J. Integr. Plant Biol. 53, 120-135. doi: 10.1111/j.1744-7909.2010. 01023.x

Byrt, C. S., Zhao, M., Kourghi, M., Bose, J., Henderson, S. W., Qiu, J., et al. (2016b). Non-selective cation channel activity of aquaporin AtPIP2;1 regulated by $\mathrm{Ca}^{2+}$ and pH. Plant Cell Environ. doi: 10.1111/pce.12832 [Epub ahead of print].

Carson, D., and Botha, F. (2002). Genes expressed in sugarcane maturing internodal tissue. Plant Cell Rep. 20, 1075-1081. doi: 10.1007/s00299-0020444-1

Carson, D. L., and Botha, F. C. (2000). Preliminary analysis of expressed sequence tags for sugarcane. Crop Sci. 40:1769. doi: 10.2135/cropsci2000. $4061769 \mathrm{x}$

Casu, R. E., Jarmey, J. M., Bonnett, G. D., and Manners, J. M. (2007). Identification of transcripts associated with cell wall metabolism and development in the stem of sugarcane by Affymetrix GeneChip sugarcane genome array expression profiling. Funct. Integr. Genomics 7, 153-167. doi: 10.1007/s10142-006-0038-Z

Chaumont, F., Barrieu, F., Herman, E. M., and Chrispeels, M. J. (1998). Characterization of a maize tonoplast aquaporin expressed in zones of cell division and elongation. Plant Physiol. 117, 1143-1152. doi: 10.1104/pp.117.4. 1143

Chaumont, F., Barrieu, F., Jung, R., and Chrispeels, M. J. (2000). Plasma membrane intrinsic proteins from Maize cluster in two sequence subgroups with differential aquaporin activity. Plant Physiol. 122, 1025-1034. doi: 10.1104/ pp.122.4.1025

Chaumont, F., Barrieu, F., Wojcik, E., Chrispeels, M. J., and Jung, R. (2001). Aquaporins constitute a large and highly divergent protein family in Maize. Plant Physiol. 125, 1206-1215. doi: 10.1104/pp.125.3.1206

Chen, L.-Q. (2014). SWEET sugar transporters for phloem transport and pathogen nutrition. New Phytol. 201, 1150-1155. doi: 10.1111/nph. 12445

Cosgrove, D. (1986). Biophysical control of plant growth. Ann. Rev. Plant Physiol. 37, 377-405. doi: 10.1146/annurev.pp.37.060186.002113

Cosgrove, D. J. (2005). Growth of the plant cell wall. Nat. Rev. Mol. Cell Biol. 6, 850-861. doi: $10.1038 / \mathrm{nrm} 1746$

Coskun, D., Britto, D. T., Huynh, W. Q., and Kronzucker, H. J. (2016). The role of silicon in higher plants under salinity and drought stress. Front. Plant Sci. 7:1072. doi: $10.3389 /$ fpls.2016.01072

Czechowski, T., Stitt, M., Altmann, T., Udvardi, M. K., and Scheible, W.-R. (2005). Genome-wide identification and testing of superior reference genes for transcript normalization in Arabidopsis. Plant Physiol. 139, 5-17. doi: 10.1104/ pp.105.063743

da Silva, M. D., Silva, R. L. D. O., Costa Ferreira Neto, J. R., Guimarães, A. C. R., Veiga, D. T., Chabregas, S. M., et al. (2013). Expression analysis of Sugarcane aquaporin genes under water deficit. J. Nucleic Acids 2013, 1-14. doi: 10.1155/ 2013/763945

Danielson, J. A, and Johanson, U. (2008). Unexpected complexity of the Aquaporin gene family in the moss Physcomitrella patens. BMC Plant Biol. 8:45. doi: 10.1186/1471-2229-8-45
De Schepper, V., De Swaef, T., Bauweraerts, I., and Steppe, K. (2013). Phloem transport: a review of mechanisms and controls. J. Exp. Bot. 64, 4839-4850. doi: 10.1093/jxb/ert302

Deshmukh, R. K., Vivancos, J., Guerin, V., Sonah, H., Labbe, C., Belzile, F., et al. (2013). Identification and functional characterization of silicon transporters in soybean using comparative genomics of major intrinsic proteins in Arabidopsis and rice. Plant Mol. Biol. 83, 303-315. doi: 10.1007/s11103-013-0087-3

Eisen, M. B., Spellman, P. T., Brown, P. O., and Botstein, D. (1998). Cluster analysis and display of genome-wide expression patterns. Genetics 95, 14863-14868.

Epstein, E. (1994). The anomaly of silicon in plant biology. Proc. Natl. Acad. Sci. U.S.A. 91, 11-17. doi: 10.1073/pnas.91.1.11

Ermawar, R. A., Collins, H. M., Byrt, C. S., Henderson, M., O’Donovan, L. A., Shirley, N. J., et al. (2015). Genetics and physiology of cell wall polysaccharides in the model C4 grass, Setaria viridis spp. BMC Plant Biol. 15:236. doi: 10.1186/ s12870-015-0624-0

Fetter, K., Van Wilder, V., Moshelion, M., and Chaumont, F. (2004). Interactions between plasma membrane aquaporins modulate their water channel activity. Plant Cell 16, 215-228. doi: 10.1105/tpc.017194

Finn, R. D., Clements, J., Arndt, W., Miller, B. L., Wheeler, T. J., Schreiber, F., et al. (2015). HMMER web server: 2015 update. Nucleic Acids Res. 43, 30-38. doi: 10.1093/nar/gkv397

Frick, A., Järvå, M., and Törnroth-Horsefield, S. (2013). Structural basis for pH gating of plant aquaporins. FEBS Lett. 587, 989-993. doi: 10.1016/j.febslet.2013. 02.038

Glasziou, K. T., and Gayler, K. R. (1972). Storage of sugars in stalks of sugar cane. Bot. Rev. 36, 471-488. doi: 10.1007/BF02859248

Grigoriev, I. V., Nordberg, H., Shabalov, I., Aerts, A., Cantor, M., Goodstein, D., et al. (2011). The genome portal of the department of energy joint genome institute. Nucleic Acids Res. 42, D26-D31.

Grof, C. P. L., Byrt, C. S., and Patrick, J. W. (2013). "Phloem transport of resources," in Sugarcane: Physiology, Biochemistry, and Functional Biology, eds P. Moore and F. Botha (Chichester: John Wiley \& Sons Ltd), 267-305.

Grof, C. P. L., and Campbell, J. A. (2001). Sugarcane sucrose metabolism: scope for molecular manipulation. Aust. J. Plant Physiol. 28, 1-12.

Hachez, C., Heinen, R. B., Draye, X., and Chaumont, F. (2008). The expression pattern of plasma membrane aquaporins in maize leaf highlights their role in hydraulic regulation. Plant Mol. Biol. 68, 337-353. doi: 10.1007/s11103-0089373-x

Hanaoka, H., Uraguchi, S., Takano, J., Tanaka, M., and Fujiwara, T. (2014). OsNIP3;1, a rice boric acid channel, regulates boron distribution and is essential for growth under boron-deficient conditions. Plant J. 78, 890-902. doi: 10.1111/ tpj.12511

Hawker, J. S. (1985). "Sucrose," in Biochemistry of Storage Carbohydrates in Green Plants, eds P. Dey and R. Dixon (New York, NY: Academic Press), 1-51.

Herbers, K., and Sonnewald, U. (1998). Molecular determinants of sink strength. Curr. Opin. Plant Biol. 1, 207-216. doi: 10.1016/S1369-5266(98)80106-4

Ho, L. C. (1988). Metabolism and compartmentation of imported sugars in sink organs in relation to sink strength. Ann. Rev. Plant Physiol. 39, 355-378. doi: 10.1146/annurev.pp.39.060188.002035

Hoffmann-Thoma, G., Hinkel, K., Nicolay, P., and Willenbrink, J. (1996). Sucrose accumulation in sweet sorghum stem internodes in relation to growth. Physiologia 97, 277-284. doi: 10.1034/j.1399-3054.1996.970210.x

Hove, R. M., Ziemann, M., and Bhave, M. (2015). Identification and expression analysis of the barley (Hordeum vulgare L.) aquaporin gene family. PLOS ONE 10:e0128025. doi: 10.1371/journal.pone.0128025

Hsiao, T. C., and Acevedo, E. (1974). Plant responses to water deficits, wateruse efficiency, and drought resistance. Agric. Meteorol. 14, 59-84. doi: 10.1016/ 0002-1571(74)90011-9

Ibraheem, O., Botha, C. E. J., and Bradley, G. (2010). In silico analysis of cis-acting regulatory elements in 5 ' regulatory regions of sucrose transporter gene families in rice (Oryza sativa Japonica) and Arabidopsis thaliana. Comput. Biol. Chem. 34, 268-283. doi: 10.1016/j.compbiolchem.2010.09.003

Javot, H., Lauvergeat, V., Santoni, V., Martin-Laurent, F., Güçlü, J., Vinh, J., et al. (2003). Role of a single aquaporin isoform in root water uptake. Plant Cell 15, 509-522. doi: 10.1105/tpc.008888

Johanson, U., and Gustavsson, S. (2002). A new subfamily of major intrinsic proteins in plants. Mol. Biol. Evol 19, 456-461. doi: 10.1093/oxfordjournals. molbev.a004101 
Johanson, U., Karlsson, M., Johansson, I., Gustavsson, S., Sjö, S., Fraysse, L., et al. (2001). The complete set of genes encoding Major Intrinsic Proteins in Arabidopsis provides a framework for a new nomenclature for Major Intrinsic Proteins in plants. Plant Physiol. 126, 1358-1369. doi: 10.1104/pp.126.4.1358

Johansson, I., Karlsson, M., Shukla, V. K., Chrispeels, M. J., Larsson, C., and Kjellbom, P. (1998). Water transport activity of the plasma membrane aquaporin PM28A is regulated by phosphorylation. Plant Cell 10, 451-459. doi: $10.1105 /$ tpc.10.3.451

Kaldenhoff, R., and Fischer, M. (2006). Functional aquaporin diversity in plants. Biochim. Biophys. Acta-Biomembr. 1758, 1134-1141. doi: 10.1016/j.bbamem. 2006.03.012

Kamiya, T., Tanaka, M., Mitani, N., Ma, J. F., Maeshima, M., and Fujiwara, T. (2009). NIP1; 1, an aquaporin homolog, determines the arsenite sensitivity of Arabidopsis thaliana. J. Biol. Chem. 284, 2114-2120. doi: 10.1074/jbc. M806881200

Karnovsky, A., Weymouth, T., Hull, T., Tarcea, V. G., Scardoni, G., Laudanna, C., et al. (2012). Metscape 2 bioinformatics tool for the analysis and visualization of metabolomics and gene expression data. Bioinforma. Orig. Pap. 28, 373-380.

Keegstra, K. (2010). Plant cell walls. Plant Physiol. 154, 483-486. doi: 10.1104/pp. 110.161240

Klie, M., and Debener, T. (2011). Identification of superior reference genes for data normalisation of expression studies via quantitative PCR in hybrid roses (Rosa hybrida). BMC Res. Notes 41:518.

Krogh, A., Larsson, B., von Heijne, G., and Sonnhammer, E. L. (2001). Predicting transmembrane protein topology with a hidden markov model: application to complete genomes. J. Mol. Biol. 305, 567-580. doi: 10.1006/jmbi.2000.4315

Lang, A. (1990). Xylem, phloem and transpiration flows in developing Apple fruits. J. Exp. Bot. 41, 645-651. doi: 10.1093/jxb/41.6.645

Lang, A., and Thorpe, M. R. (1989). Xylem, phloem and transpiration flows in a grape: application of a technique for measuring the volume of attached fruits to high resolution using archimedes'. Principle. J. Exp. Bot. 40, 1069-1078. doi: $10.1093 / j x b / 40.10 .1069$

Leitao, L., Prista, C., Moura, T. F., Loureiro-Dias, M. C., and Soveral, G. (2012). Grapevine aquaporins: gating of a tonoplast intrinsic protein (TIP2;1) by cytosolic pH. PLoS ONE 7:e33219. doi: 10.1371/journal.pone.0033219

Lescot, M., Déhais, P., Thijs, G., Marchal, K., Moreau, Y., Van De Peer, Y., et al. (2002). PlantCARE, a database of plant cis-acting regulatory elements and a portal to tools for in silico analysis of promoter sequences. Nucleic Acids Res. 30, 325-327. doi: 10.1093/nar/30.1.325

Li, P., and Brutnell, T. P. (2011). Setaria viridis and Setaria italica, model genetic systems for the Panicoid grasses. J. Exp. Bot. 62, 3031-3037. doi: 10.1093/jxb/ err096

Li, R. Y., Ago, Y., Liu, W. J., Mitani, N., Feldmann, J., McGrath, S. P., et al. (2009). The rice aquaporin Lsil mediates uptake of methylated arsenic species. Plant Physiol. 150, 2071-2080. doi: 10.1104/pp.109.140350

Liu, D., Tu, L., Wang, L., Li, Y., Zhu, L., and Zhang, X. (2008). Characterization and expression of plasma and tonoplast membrane aquaporins in elongating cotton fibers. Plant Cell Rep. 27, 1385-1394. doi: 10.1007/s00299-008-0545-6

Liu, Q. P., and Zhu, Z. J. (2010). Functional divergence of the NIP III subgroup proteins involved altered selective constraints and positive selection. BMC Plant Biol. 10:256. doi: 10.1186/1471-2229-10-256

Luu, D. T., and Maurel, C. (2005). Aquaporins in a challenging environment: molecular gears for adjusting plant water status. Plant Cell Environ. 28, 85-96. doi: 10.1111/j.1365-3040.2004.01295.X

Ma, J. F., Mitani, N., Nagao, S., Konishi, S., Tamai, K., Iwashita, T., et al. (2004). Characterization of the silicon uptake system and molecular mapping of the silicon transporter gene in rice. Plant Physiol. 136, 3284-3289. doi: 10.1104/pp. 104.047365

Ma, J. F., Tamai, K., Yamaji, N., Mitani, N., Konishi, S., Katsuhara, M., et al. (2006). A silicon transporter in rice. Nature 440, 688-691. doi: 10.1038/nature 04590

Ma, J. F., and Yamaji, N. (2008). Functions and transport of silicon in plants. Cell. Mol. Life Sci. 65, 3049-3057. doi: 10.1007/s00018-008-7580-x

Ma, J. F., Yamaji, N., Mitani, N., Xu, X.-Y., Su, Y.-H., Mcgrath, S. P., et al. (2008). Transporters of arsenite in rice and their role in arsenic accumulation in rice grain. Proc. Natl. Acad. Sci. U.S.A. 105, 9931-9935. doi: 10.1073/pnas. 0802361105
Malz, S., and Sauter, M. (1999). Expression of two PIP genes in rapidly growing internodes of rice is not primarily controlled by meristem activity or cell expansion. Plant Mol. Biol. 40, 985-995. doi: 10.1023/A:1006265528015

Martin, A. P., Palmer, W. M., Brown, C., Abel, C., Lunn, J. E., Furbank, R. T., et al. (2016). A developing Setaria viridis internode: an experimental system for the study of biomass generation in a C4 model species. Biotechnol. Biofuels 9, 1-12. doi: 10.1186/s13068-016-0457-6

Maurel, C. (1997). Aquaporins and water permeability of plant membranes. Annu. Rev. Plant Physiol. Plant Mol. Biol. 48, 399-429. doi: 10.1146/annurev.arplant. 48.1.399

Maurel, C., Javot, H., Lauvergeat, V., Gerbeau, P., Tournaire, C., Santoni, V., et al. (2002). Molecular physiology of aquaporins in plants. Int. Rev. Cytol. 215, 105-148. doi: 10.1016/S0074-7696(02)15007-8

Maurel, C., Verdoucq, L., Luu, D.-T. T., and Santoni, V. (2008). Plant aquaporins: membrane channels with multiple integrated functions. Annu. Rev. Plant Biol. 59, 595-624. doi: 10.1146/annurev.arplant.59.032607.092734

McCormick, A. J., Watt, D. A., and Cramer, M. D. (2009). Supply and demand: sink regulation of sugar accumulation in sugarcane. J. Exp. Bot. 60, 357-364. doi: $10.1093 /$ jxb/ern310

Milne, R. J., Byrt, C. S., Patrick, J. W., and Grof, C. P. L. (2013). Are sucrose transporter expression profiles linked with patterns of biomass partitioning in Sorghum phenotypes? Front. Plant Sci. 4:223. doi: 10.3389/fpls.2013.00223

Milne, R. J., Offler, C. E., Patrick, J. W., and Grof, C. P. L. (2015). Cellular pathways of source leaf phloem loading and phloem unloading in developing stems of Sorghum bicolor in relation to stem sucrose storage. Funct. Plant Biol. 42, 957-970. doi: 10.1071/FP15133

Mitani, N. (2005). Uptake system of silicon in different plant species. J. Exp. Bot. 56, 1255-1261. doi: 10.1093/jxb/eri121

Mizuno, H., Kasuga, S., and Kawahigashi, H. (2016). The sorghum SWEET gene family: stem sucrose accumulation as revealed through transcriptome profiling. Biotechnol. Biofuels 9, 1-12. doi: 10.1186/s13068-016-0546-6

Moore, P. H. (1995). Temporal and spatial regulation of sucrose accumulation in the sugarcane stem. Aust. J. Plant Physiol 22, 661-679. doi: 10.1071/PP9950661

Moore, P. H., and Botha, F. C. (2013). Sugarcane: Physiology, Biochemistry and Functional Biology. Hoboken, NJ: John Wiley \& Sons.

Moore, P. H., and Cosgrove, D. J. (1991). Developmental changes in cell and tissue water relations parameters in storage parenchyma of sugarcane. Plant Physiol. 96, 794-801. doi: 10.1104/pp.96.3.794

Mosa, K. A., Kumar, K., Chhikara, S., Mcdermott, J., Liu, Z. J., Musante, C., et al. (2012). Members of rice plasma membrane intrinsic proteins subfamily are involved in arsenite permeability and tolerance in plants. Transgenic Res. 21, 1265-1277. doi: 10.1007/s11248-012-9600-8

Papini-Terzi, F. F. S., Rocha, F. R. F., Vencio, R. R. Z., Felix, J. J. M., Branco, D. S., Waclawovsky, A. J. A., et al. (2009). Sugarcane genes associated with sucrose content. BMC Genomics 10:120. doi: 10.1186/1471-2164-10-120

Patrick, J. W. (1997). Phloem unloading: Sieve element unloading and post-sieve element transport. Annu. Rev. Plant Physiol. Plant Mol. Biol. 48, 191-222. doi: 10.1146/annurev.arplant.48.1.191

Patrick, J. W., Botha, F. C., and Birch, R. G. (2013). Metabolic engineering of sugars and simple sugar derivatives in plants. Plant Biotechnol. J. 11, 142-156. doi: $10.1111 /$ pbi.12002

Péret, B., Li, G., Zhao, J., Band, L. R., Voß, U., Postaire, O., et al. (2012). Auxin regulates aquaporin function to facilitate lateral root emergence. Nat. Cell Biol. 14, 991-998. doi: 10.1038/ncb2573

Pfeiffer, T. W., Bitzer, M. J., Toy, J. J., and Pedersen, J. F. (2010). Heterosis in sweet sorghum and selection of a new sweet sorghum hybrid for use in syrup production in appalachia. Crop Sci. 50, 1788-1794. doi: 10.2135/cropsci2009.09. 0475

Rae, A. L., Grof, C. P. L., and Casu, R. E. (2005). Sucrose accumulation in the sugarcane stem: pathways and control points for transport and compartmentation. Field Crop. Res. 92, 159-168. doi: 10.1016/j.fcr.2005.01.027

Rae, A. L., Jackson, M. A., Nguyen, C. H., and Bonnett, G. D. (2009). Functional specialization of vacuoles in sugarcane leaf and stem. Trop. Plant Biol. 2, 13-22. doi: 10.1007/s12042-008-9019-9

Reddy, P. S., Rao, T. S. R. B., Sharma, K. K., and Vadez, V. (2015). Genome-wide identification and characterization of the aquaporin gene family in Sorghum bicolor (L.). Plant Gene 1, 18-28. doi: 10.1016/j.plgene.2014.12.002 
Reinders, A., Sivitz, A. B., Starker, C. G., Gantt, J. S., and Ward, J. M. (2008). Functional analysis of LjSUT4, a vacuolar sucrose transporter from Lotus japonicus. Plant Mol. Biol. 68, 289-299. doi: 10.1007/s11103-008-9370-0

Rohwer, J. M., and Botha, F. C. (2001). Analysis of sucrose accumulation in the sugar cane culm on the basis of in vitro kinetic data. Biochem. J. 358, 437-445. doi: 10.1042/bj3580437

Sakurai, J., Ishikawa, F., Yamaguchi, T., Uemura, M., and Maeshima, M. (2005). Identification of 33 rice aquaporin genes and analysis of their expression and function. Plant Cell Physiol. 46, 1568-1577. doi: 10.1093/pcp/pci172

Schmalstig, J. G., and Cosgrove, D. J. (1990). Coupling of solute transport and cell expansion in pea stems. Plant Physiol. 94, 1625-1633. doi: 10.1104/pp.94.4.1625

Schuurmans, J. A. M., van Dongen, J. T., Rutjens, B. P. W., Boonman, A., Pieterse, C. M. J., and Borstlap, A. C. (2003). Members of the aquaporin family in the developing pea seed coat include representatives of the PIP, TP and NIP subfamilies. Plant Mol. Biol. 53, 655-667. doi: 10.1023/B:PLAN.0000019070. 60954.77

Siefritz, F., Biela, A., Eckert, M., Otto, B., Uehlein, N., and Kaldenhoff, R. (2001). The tobacco plasma membrane aquaporin NtAQP1. J. Exp. Bot. 52, 1953-1957. doi: $10.1093 /$ jexbot/52.363.1953

Slewinski, T. L. (2011). Diverse functional roles of monosaccharide transporters and their homologs in vascular plants: a physiological perspective. Mol. Plant 4, 641-662. doi: 10.1093/mp/ssr051

Slewinski, T. L. (2012). Non-structural carbohydrate partitioning in grass stems: a target to increase yield stability, stress tolerance, and biofuel production. J. Exp. Bot. 63, 4647-4670. doi: 10.1093/jxb/ers124

Somerville, C., Youngs, H., Taylor, C., Davis, S. C., and Long, S. P. (2010). Feedstocks for lignocellulosic biofuels. Science. 329, 790-792. doi: 10.1126/ science. 1189268

Spyropoulos, I. C., Liakopoulos, T. D., Bagos, P. G., and Hamodrakas, S. J. (2004). TMRPres2D: High quality visual representation of transmembrane protein models. Bioinformatics 20, 3258-3260. doi: 10.1093/bioinformatics/bth358

Takano, J., Wada, M., Ludewig, U., Schaaf, G., Von Wirén, N., and Fujiwara, T. (2006). The Arabidopsis major intrinsic protein NIP5; 1 is essential for efficient boron uptake and plant development under boron limitation. Plant Cell 18, 1498-1509. doi: 10.1105/tpc.106.041640

Tarpley, L., Vietor, D. M., Tarpley, L., Vietor, D., Miller, F., Guimarães, C., et al. (2007). Compartmentation of sucrose during radial transfer in mature sorghum culm. BMC Plant Biol. 7:33. doi: 10.1186/1471-2229-7-33

Törnroth-Horsefield, S., Wang, Y., Hedfalk, K., Johanson, U., Karlsson, M., Tajkhorshid, E., et al. (2006). Structural mechanism of plant aquaporin gating. Nature 439, 688-694. doi: 10.1038/nature04316

Tournaire-Roux, C., Sutka, M., Javot, H. H., Gout, E. E., Gerbeau, P., Luu, D.-T. T., et al. (2002). Cytosolic $\mathrm{pH}$ regulates root water transport during anoxic stress through gating of aquaporins. Nature 425, 187-194.

Turgeon, R. (2010). The puzzle of phloem pressure. Plant Physiol. 154, 578-581. doi: 10.1104/pp.110.161679

Uehlein, N., Lovisolo, C., Siefritz, F., and Kaldenhoff, R. (2003). The tobacco aquaporin NtAQP1 is a membrane $\mathrm{CO}_{2}$ pore with physiological functions. Nature 425, 734-737. doi: 10.1038/nature02027

Viola, R., Roberts, A. G., Haupt, S., Gazzani, S., Hancock, R. D., Marmiroli, N., et al. (2001). Tuberization in potato involves a switch from apoplastic to symplastic phloem unloading. Plant Cell 13, 385-398. doi: 10.1105/tpc.13. 2.385

Vogel, J. (2008). Unique aspects of the grass cell wall. Curr. Opin. Plant Biol. 11, 301-307. doi: 10.1016/j.pbi.2008.03.002
Waclawovsky, A. J., Sato, P. M., Lembke, C. G., Moore, P. H., and Souza, G. M. (2010). Sugarcane for bioenergy production: an assessment of yield and regulation of sucrose content. Plant Biotechnol. J. 8, 263-276. doi: 10.1111/j. 1467-7652.2009.00491.x

Walsh, K. B., Sky, R. C., and Brown, S. M. (2005). The anatomy of the pathway of sucrose unloading within the sugarcane stalk. Funct. Plant Biol. 32, 367-374. doi: 10.1071/FP04102

Wei, W. X., Alexandersson, E., Golldack, D., Miller, A. J., Kjellborn, P. O., and Fricke, W. (2007). HvPIP1;6, a barley (Hordeum vulgare L.) plasma membrane water channel particularly expressed in growing compared with non-growing leaf tissues. Plant Cell Physiol. 48, 1132-1147. doi: 10.1093/pcp/pcm083

Welbaum, G. E., and Meinzer, F. C. (1990). Compartmentation of solutes and water in developing sugarcane stalk tissue. Plant Physiol. 93, 1147-1153. doi: 10.1104/pp.93.3.1147

Welbaum, G. E., Meinzer, F. C., Grayson, R. L., and Thornham, K. T. (1992). Evidence for the consequences of a barrier to solute diffusion between the apoplast and vascular bundles in sugarcane stalk tissue. Funct. Plant Biol. 19, 611-623.

Werner, D., Gerlitz, N., and Stadler, R. (2011). A dual switch in phloem unloading during ovule development in Arabidopsis. Protoplasma 248, 225-235. doi: 10. 1007/s00709-010-0223-8

Wingenter, K., Schulz, A., Wormit, A., Wic, S., Trentmann, O., Hoermiller, I. I., et al. (2010). Increased activity of the vacuolar monosaccharide transporter TMT1 alters cellular sugar partitioning, sugar signaling, and seed yield in Arabidopsis. Plant Physiol. 154, 665-677. doi: 10.1104/pp.110.162040

Wood, R., Patrick, J. W., and Offler, C. E. (1994). The cellular pathway of shortdistance transfer of photosynthates and potassium in the elongating stem of Phaseolus vulgaris L. Stem anatomy, solute transport and pool sizes. Ann. Bot. 73, 151-160. doi: 10.1006/anbo.1994.1018

Yonekura-Sakakibara, K., and Saito, K. (2013). Transcriptome coexpression analysis using ATTED-II for integrated transcriptomic/metabolomic analysis. Methods Mol. Biol. 1011, 317-326. doi: 10.1007/978-1-62703-414-2_25

Zelazny, E., Borst, J. W., Muylaert, M., Batoko, H., Hemminga, M. A., and Chaumont, F. (2007). FRET imaging in living maize cells reveals that plasma membrane aquaporins interact to regulate their subcellular localization. Proc. Natl. Acad. Sci. U.S.A. 104, 12359-12364. doi: 10.1073/pnas.07011 80104

Zhang, W.-H., Zhou, Y., Dibley, K. E., Tyerman, S. D., Furbank, R. T., Patrick, J. W., et al. (2007). Nutrient loading of developing seeds. Funct. Plant Biol. 34, 314-331. doi: 10.1071/FP06271

Zhao, X. Q., Mitani, N., Yamaji, N., Shen, R. F., and Ma, J. F. (2010). Involvement of silicon influx transporter OsNIP2;1 in selenite uptake in rice. Plant Physiol. 153, 1871-1877. doi: 10.1104/pp.110.157867

Conflict of Interest Statement: The authors declare that the research was conducted in the absence of any commercial or financial relationships that could be construed as a potential conflict of interest.

Copyright (c) 2016 McGaughey, Osborn, Chen, Pegler, Tyerman, Furbank, Byrt and Grof. This is an open-access article distributed under the terms of the Creative Commons Attribution License (CC BY). The use, distribution or reproduction in other forums is permitted, provided the original author(s) or licensor are credited and that the original publication in this journal is cited, in accordance with accepted academic practice. No use, distribution or reproduction is permitted which does not comply with these terms. 